\title{
A surgical polypragmasy: Koninckx PR, Corona R, Timmerman D, Verguts J, Adamyan L. Peritoneal full-conditioning reduces postoperative adhesions and pain: a randomised controlled trial in deep endometriosis surgery. J Ovarian Res. 2013 Dec 11;6(1):90
}

\author{
Ospan A Mynbaev ${ }^{1,3^{*}}$, Peter Biro ${ }^{2}$, Marina Yu Eliseeva ${ }^{3}$, Andrea Tinelli ${ }^{4}$, Antonio Malvasi ${ }^{5}$, Ioannis P Kosmas ${ }^{6}$, \\ Mykhailo V Medvediev ${ }^{7}$, Tatiana I Babenko ${ }^{8}$, Madina I Mazitova ${ }^{9}$, Sergei S Simakov ${ }^{1}$ and Michael Stark ${ }^{10}$
}

\section{Dear Sir,}

In clinical trials most adhesion prevention methods fail. Therefore we have read the article by Koninckx et al. [1] with great interest. They aim "... to perform a translational proof of concept trial to investigate the effect of full-conditioning (FC) in the human upon $\mathrm{CO}_{2}$ resorption during surgery, ...".

Congratulations to the authors are in order for their valuable clinical results which have demonstrated the efficiency of their attempts to prevent postsurgical adhesions, reducing pain and modulated posttraumatic inflammation with lower postoperative C-reactive protein (CRP) values and accelerated recovery. Since huge obstacles in the setup of clinical studies are met when second-look laparoscopy (SLL) is required, most studies evaluate the efficiency of adhesion prevention adjuvants on the basis of experiments only. It is indeed difficult to organize such kind of clinical trials due to both severe ethical and financial issues and patient requirement difficulties. Therefore, clinical trials aimed to evaluate postsurgical adhesion formation by SLL should be based on a well-defined study question, a distinct design and strictly specified patient selection, all of which may lead

\footnotetext{
* Correspondence: ospanmynbaev@hotmail.com

${ }^{1}$ The International Translational Medicine \& Biomodeling Research Group, Department of Applied Mathematics, Moscow Institute of Physics \& Technology (State University), 9 institutsky per, Dolgoprudny, Moscow Region 141700, Russia

${ }^{3}$ The Department of Obstetrics, Gynecology \& Reproductive Medicine, Peoples' Friendship University of Russia, 21/3 Miklukho-Maklay str, Moscow 117198, Russia

Full list of author information is available at the end of the article
}

to evidence-based conclusions, albeit in a limited number of homogenous population.

However, some shortcomings of this study [1], which might lead to misleading conclusions, and the authors' disregard of well-known undesirable $\mathrm{N}_{2} \mathrm{O}$ side effects have coerced us to write this letter.

Professor Koninckx is an outstanding, worldwide authority in this field who performs high-quality surgical treatment of deep endometriosis. Therefore we may safely assume that for deep endometriosis excision in both groups, identical surgical procedures were performed and that presurgical randomization and postsurgical follow-up were also done up to standard.

However, the patients in the FC group experienced surgical polypragmasy, namely: 1 ) a humidified pneumoperitoneum gas mixture $\left(86 \% \mathrm{CO}_{2}+10 \% \mathrm{~N}_{2} \mathrm{O}+4 \% \mathrm{O}_{2}\right)$ with controlled gas temperature $\left(31^{\circ} \mathrm{C}\right)$; 2) peritoneal cooling (up to $30^{\circ} \mathrm{C}$ ) by sprinkling $2-3 \mathrm{ml} / \mathrm{min}$ of Ringers lactate with heparin (1000 IU/L) at room temperature; 3) a Hyalobarrier gel (HBG) application, and 4) $5 \mathrm{mg}$ of dexamethasone administered intramuscularly at the end of surgery. The women in the control group however, were operated by standard laparoscopy with humidified $\mathrm{CO}_{2}$ only and these two completely different treatment approaches were compared. Subsequently, according to the authors' conclusions, successful adhesion prevention treatment was estimated by FC only.

We quote: "This translational research confirms in the human the efficacy of $\mathrm{FC}$ in reducing $\mathrm{CO}_{2}$ resorption and adhesions with in addition less postoperative pain, 
lower postoperative CRP concentrations and an accelerated recovery" [1].

It is difficult to identify the cause of the beneficial adhesion prevention impact because of the excessive combination of several factors. Indeed, it is difficult to accept the authors' conclusion that the adhesion prevention effect is related with FC only, since in these patients HBG was also applied and dexamethasone was administered. Therefore, the abstract section does not reflect their results at all and may lead JOR readers astray.

Another limitation of this study lies in the small number of patients and the complexity of the adhesion score. In the compared groups it is difficult to distinguish between size and severity of adhesions separately. Moreover, upon initial surgery, most patients had already had adhesions resulting from previous surgery. It is a well-known fact that the adhesion score analysis after adhesiolysis is different from that of adhesions after first surgery. It is quite clear that all of these factors, combined with the population heterogeneity in these groups which only have a small number of patients, may lead to biased results.

We previously demonstrated that reduced blood gas changes during $\mathrm{CO}_{2}$ pneumoperitoneum are associated with mixed gas insufflation (MGI) since even a small concentration of $\mathrm{O}_{2}$ added to $\mathrm{CO}_{2}$ results in lower end tidal $\mathrm{CO}_{2}\left(\mathrm{P}_{\mathrm{ET}} \mathrm{CO}_{2}\right)$ values and slight changes in blood gas parameters in comparison with those of pure $\mathrm{CO}_{2}$ insufflation in rabbits [2,3]. Also, MGI has a significant impact on ventilation parameters [4]. Subsequently, it is obvious that during surgery, patients in the FC group require less increased tidal volume (TV) and lower ventilation frequency than patients in the standard pneumoperitoneum group. However, this conclusion should be drawn based upon a comprehensive analysis of anesthesiological management including full respiratory and blood gas, acid base parameters without combining raw data of $\mathrm{P}_{\mathrm{ET}} \mathrm{CO}_{2}$, TV and frequency of ventilation.

In comparison with the traditional mechanism of adhesions (Figure 1A), $\mathrm{N}_{2} \mathrm{O}$ impact on adhesion formation may be related with the activation of several $\mathrm{N}_{2} \mathrm{O}$ induced pathways (Figure 1B) with rise of Hcys content [5] and an increased cysteine concentration [6], which then possibly results in weakened collagen cross-linking in the collagen network between fibroblasts [7]; $\mathrm{N}_{2} \mathrm{O}$ induced-oxidative stress and DNA damage [8]; apoptosis by caspase-3 activation [9] in adhesion fibroblasts with increased genome instability.

The authors stated that $\mathrm{N}_{2} \mathrm{O}$ is safer than $\mathrm{CO}_{2}$ due to its high solubility in water and the higher lung exchange capacity [1]. However, according to available literature, the administration of $\mathrm{N}_{2} \mathrm{O}$ is associated with neuroapoptotic/neurotoxic [5,6] genotoxic effects [8] and changes in cobalamin (Vitamin B12), methionine synthase and Hcys metabolism [5,6] the latter being an $\alpha$-amino acid biosynthesized from methionine by catabolism.

Through these signaling pathways an increased concentration of blood $\mathrm{N}_{2} \mathrm{O}[5,6]$ is associated with the expansion of air-filled spaces such as bowel, and pneumothorax $[10,11]$; a dose-dependent depression of the ventilatory response to hypoxemia [12]; increased DNA damage [8]; endothelial dysfunction with elevated procoagulant status [13] with increased risk of thromboembolism, atherosclerosis and cardiovascular diseases $[5,6,13,14]$ and long term risk of myocardial infarctions [15].

It can be put forward that multiple blood clots in the lesion sites will be stabilized as long-term fibrinogenic adhesions transforming later to fibrotic adhesions (Figure $1 \mathrm{C}$ ) due to changes of the vascular endothelium surface from an anti- to a procoagulant status, the reactivation of blood platelets involving several intrinsic and extrinsic targets in coagulation and fibrinolysis, resulting in alterations of blood clot/fibrin clot structure, and its increased resistance to fibrinolysis [13].

Surprisingly, several risk factors are related with reproductive functioning, such as: a reduced fertility [16]; an elevated risk of spontaneous abortion [17]; in rats, changes in the luteinizing hormone releasing hormone [18]; $\mathrm{N}_{2} \mathrm{O}$-induced teratogenicity [19], are claimed to be a result of $\mathrm{N}_{2} \mathrm{O}$ administration.

These $\mathrm{N}_{2} \mathrm{O}$ effects, combined with other factors due to polypragmasy with multiple compounds of surgical procedures, may lead to unexpected and undesirable side effects when, in various circumstances, its action pathways remain unclear.

Although the clinical relevance of the unfavorable side effects of $\mathrm{N}_{2} \mathrm{O}$ remains undetermined $[12,20]$ we should be prudent in introducing $\mathrm{N}_{2} \mathrm{O}$ as a safe additive compound for the pneumoperitoneum. Moreover, if we take into account the metabolic, procoagulant and DNA damaging properties of $\mathrm{N}_{2} \mathrm{O}$ it is clear that a spectrum of beneficial and undesirable effects of $\mathrm{N}_{2} \mathrm{O}$ being insufflated intraperitoneally under pressure have not yet been fully appreciated.

We suggest that the influence of $\mathrm{N}_{2} \mathrm{O}$ as an additional component gas for the pneumoperitoneum should be investigated in different animal models evaluating a wide range of physiological parameters including blood gases, acid base balance, oxygen/oximetry and metabolite values and this in well-designed experimental studies. Special attention should be given to local intraperitoneal changes such as oxidative stress parameters, the response of peritoneal macrophages and the role of immune reaction pathways. These studies are needed to demonstrate the impact of both, $\mathrm{CO}_{2}$ and $\mathrm{N}_{2} \mathrm{O}$ on postsurgical adhesions and the homeostasis. This combination might indeed reduce or even solve the adhesion problem, but as long as experimental studies by other research groups do not 


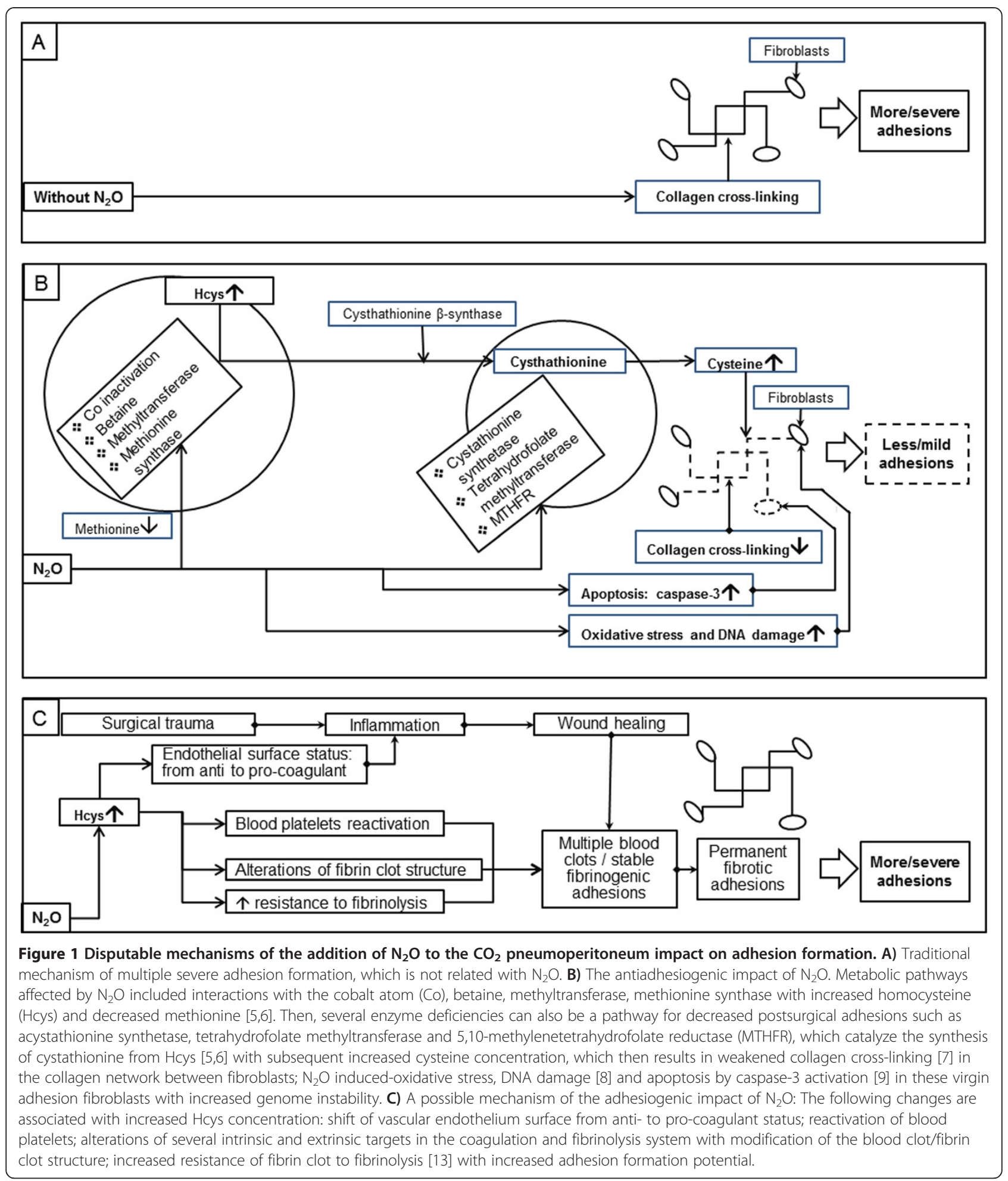

prove the benefits nor examine the calculated risks, we should continue to use $\mathrm{CO}_{2}$, which is a well-established gas with known pathophysiological mechanisms.

At NESA, we believe in, and are initiating evidencebased studies toward the standardization of surgical procedures in order to avoid the implementation of superfluous technologies instead of relying on surgical excellence. The concept of simple surgical procedures performed with a limited number of instruments and surgical equipment was suggested in cases where an 
adhesion prevention strategy should be implemented by a personalized approach taking into account individual genetic and constitutional predispositions. Any surgical tool, procedure or combination of gases should be introduced only after it has been proved to add value to existing ones; therefore we should continue to examine the effect of gas mixtures as potential agents leading to adhesion free endoscopy.

In conclusion, this FC clinical trial definitely is a step forward in the surgical treatment of severe deep endometriosis. Future studies with simplified MGI may cast further light on the mechanism of this strategy's adhesion prevention impact since pure $\mathrm{CO}_{2}$ during laparoscopic surgery produces severe acidosis, blood gas and acid base changes with increased intraperitoneal insufflation pressure.

\section{Abbreviations}

CRP: C-reactive protein; SLL: Second look laparoscopy; FC: Full-conditioning; MGl: Mixed gas insufflation; $\mathrm{CO}_{2}$ : Carbon dioxide; $\mathrm{N}_{2} \mathrm{O}$ : Nitrous oxide;

$\mathrm{O}_{2}$ : Oxygen; HBG: Hyalobarrier gel; JOR: Journal of ovarian research; TV: Tidal volume; Hcys: Homocysteine; DNA: Deoxyribonucleic acid; NESA: New European Surgical Academy; Polypragmasy: The use of multiple therapeutic modalities to manage a single condition. ("Segen's Medical Dictionary. (c) 2012 Farlex, Inc. All rights reserved).

\section{Competing interests}

The authors declare that they have no competing interests.

\section{Authors' contributions}

In the design of this letter all authors contributed equally and approved the final manuscript.

\footnotetext{
Author details

${ }^{1}$ The International Translational Medicine \& Biomodeling Research Group, Department of Applied Mathematics, Moscow Institute of Physics \& Technology (State University), 9 institutsky per, Dolgoprudny, Moscow Region 141700, Russia. ${ }^{2}$ The Institute of Anaesthesiology, University Hospital, 100 Rämistrasse, Zürich CH-8091, Switzerland. ${ }^{3}$ The Department of Obstetrics, Gynecology \& Reproductive Medicine, Peoples' Friendship University of Russia, 21/3 Miklukho-Maklay str, Moscow 117198, Russia. ${ }^{4}$ The Department of Obstetrics and Gynaecology, Division of Experimental Endoscopic Surgery, Imaging, Minimally Invasive Therapy and Technology, Vito Fazzi Hospital, Piazza Muratore, Lecce 73100, Italy. ${ }^{5}$ Department of Obstetrics and Gynecology, Santa Maria Hospital, 314/A Via Alcide De Gasperi, Bari 70125, Italy. ${ }^{6}$ The Department of Obstetrics \& Gynecology, Xatzikosta General Hospital, Avenue General Makriyannis, loannina 45001, Greece. ${ }^{7}$ The Department of Obstetrics \& Gynecology, State Establishment "Dnepropetrovsk Medical Academy of Health Ministry of Ukraine", 9 Dzerzhinky str, Dnepropetrovsk 49044, Ukraine. ${ }^{8}$ The Department of Obstetrics \& Gynecology, Stavropol State Medical University, 310 Mira str, Stavropol 355017, Russia. ${ }^{9}$ The Department of Obstetrics and Gynecology, Kazan State Medical Academy, 11/1 Mushtary, Kazan 420012, Russia. ${ }^{10}$ The New European Surgical Academy, 21 Unter den Linden, Berlin 10117, Germany.
}

Received: 17 January 2014 Accepted: 4 March 2014 Published: 10 March 2014

\section{References}

1. Koninckx PR, Corona R, Timmerman D, Verguts J, Adamyan L: Peritoneal full-conditioning reduces postoperative adhesions and pain: a randomised controlled trial in deep endometriosis surgery. J Ovarian Res 2013, 6(1):90.

2. Mynbaev OA, Adamyan LV, Mailova K, Vanacker B, Koninckx PR: Effects of adding small amounts of oxygen to a carbon dioxide-pneumoperitoneum of increasing pressure in rabbit ventilation models. Fertil Steril 2009, 92(2):778-784.
3. Mynbaev OA, Molinas CR, Adamyan LV, Vanacker B, Koninckx PR: Reduction of $\mathrm{CO}(2)$-pneumoperitoneum-induced metabolic hypoxaemia by the addition of small amounts of $\mathrm{O}(2)$ to the $\mathrm{CO}(2)$ in a rabbit ventilated model. A preliminary study. Hum Reprod 2002, 17(6):1623-1629.

4. Mynbaev OA, Molinas CR, Adamyan LV, Vanacker B, Koninckx PR: Pathogenesis of $\mathrm{CO}$ (2) pneumoperitoneum-induced metabolic hypoxemia in a rabbit model. J Am Assoc Gynecol Laparosc 2002, 9(3):306-314.

5. Badner N, Drader K, Freeman D, Spence JD: The use of intraoperative nitrous oxide leads to postoperative increases in plasma homocysteine. Anesth Analg 1998, 87:711-713.

6. Baum VC: When nitrous oxide is no laughing matter: nitrous oxide and pediatric anesthesia. Paediatr Anaesth 2007, 17(9):824-830.

7. Diamond MP, El-Hammady E, Wang R, Saed G: Metabolic regulation of collagen I in fibroblasts isolated from normal peritoneum and adhesions by dichloroacetic acid. Am J Obstet Gynecol 2002, 187(6):1456-1460.

8. Wrońska-Nofer T, Nofer JR, Jajte J, Dziubałtowska E, Szymczak W, Krajewski W, Wąsowicz W, Rydzyński K: Oxidative DNA damage and oxidative stress in subjects occupationally exposed to nitrous oxide (N(2)O). Mutat Res 2012, 731(1-2):58-63.

9. Zhen Y, Dong Y, Wu X, Xu Z, Lu Y, Zhang Y, Norton D, Tian M, Li S, Xie Z: Nitrous oxide plus isoflurane induces apoptosis and increases betaamyloid protein levels. Anesthesiology 2009, 111(4):741-752.

10. Munson ES: Transfer of nitrous oxide into body air cavities. Br J Anaesth 1974, 46(3):202-209.

11. Kaur S, Cortiella J, Vacanti CA: Diffusion of nitrous oxide into the pleural cavity. Br J Anaesth 2001, 87(6):894-896.

12. Tobias JD: Applications of nitrous oxide for procedural sedation in the pediatric population. Pediatr Emerg Care 2013, 29(2):245-265.

13. Karolczak K, Olas B: Mechanism of action of homocysteine and its thiolactone in hemostasis system. Physiol Res 2009, 58(5):623-633.

14. Clarke R, Daly L, Robinson K, Naughten E, Cahalane S, Fowler B, Graham I: Hyperhomocysteinemia: a risk factor for vascular disease. N Engl I Med 1991, 324:1149-1155.

15. Leslie K, Myles PS, Chan MT, Forbes A, Paech MJ, Peyton P, Silbert BS, Williamson E: Nitrous oxide and longterm morbidity and mortality in the ENIGMA trial. Anesth Analg 2011, 112(2):387-393.

16. Rowland AS, Baird DD, Weinberg CR, Shore DL, Shy CM, Wilcox AJ: Reduced fertility among women employed as dental assistants exposed to high levels of nitrous oxide. N Engl J Med 1992, 327(14):993-997.

17. Rowland AS, Baird DD, Shore DL, Weinberg CR, Savitz DA, Wilcox AJ: Nitrous oxide and spontaneous abortion in female dental assistants. Am J Epidemiol 1995, 141(6):531-538.

18. Kugel G, Letelier C, Zive MA, King JC: Nitrous oxide and infertility. Anesth Prog 1990, 37(4):176-180.

19. Fujinaga M, Baden JM: Methionine prevents nitrous oxide-induced teratogenicity in rat embryos grown in culture. Anesthesiology 1994, 81(1):184-189.

20. Myles PS: Nitrous oxide: deep in the zone of uncertainty. Anesthesiology 2013, 119(1):1-3.

doi:10.1186/1757-2215-7-29

Cite this article as: Mynbaev et al:: A surgical polypragmasy: Koninckx PR, Corona R, Timmerman D, Verguts J, Adamyan L. Peritoneal full-conditioning reduces postoperative adhesions and pain: a randomised controlled trial in deep endometriosis surgery. J Ovarian Res. 2013 Dec 11;6(1):90. Journal of Ovarian Research 2014 7:29. 